\title{
Impact of malocclusion on self-esteem (SE) and orthognathic quality of life (OQOL) amongst dental undergraduate students
}

\author{
Kahkeshan Nausheen ${ }^{1}$, Sayyeda Madiha ${ }^{2}$, Harneet Kaur ${ }^{3 *}$ \\ ${ }^{1,2}$ Former Intern, ${ }^{3}$ Associate Professor, Dept. of Orthodontics, Faculty of Dentistry, Jamia Millia Islamia, New Delhi, India
}

*Corresponding Author: Harneet Kaur

Email: hkaur@jmi.ac.in

\begin{abstract}
Introduction: While malocclusion exerts both physical and emotional effects on laypersons, with increasing awareness of malocclusion and its aesthetic impairment, there must be psychological impact of malocclusion amongst students entering into a dental school. The null hypothesis proposed was increasing grades of the course results in higher self esteem and poorer quality of life amongst students pursuing on undergraduate course in dentistry.

Aim: The aim was to determine the relationship between severity of malocclusion, self esteem (SE) and orthognathic quality of life (OQoL) among female dental undergraduate students.

Material and Methods: The study sample was divided batchwise into four groups according to the grades. Written questionnaires for SE and OQoL were given to 83 female undergraduate students with no craniofacial anomalies, medical problems, and history of previous orthodontic treatment. To determine the severity of malocclusion, the subjects were later examined for Dental Aesthetic Index (DAI) score. Descriptive statistics for DAI, SE and OQOL were performed and elements of each group were compared using ANOVA. Spearman Rank Correlation coefficient was done to measure the level of association between the variables.

Results \& Discussion: While 3rd year students presented with higher DAI and least OQOL score, there was a statistically significant negative correlation between DAI and OQOL, indicating more negative psychological impact of malocclusion with learning. Interns had higher SE and maximum OQoL. ANOVA results showed only statistically significant difference between the groups for SE indicating more armour propre with training and maturity. However, no significant correlation was noted between SE and OQol.

Conclusions: Malocclusion does hamper the quality of life but increasing grades and cumulative understanding also influence the self esteem amongst dental undergraduates.
\end{abstract}

Keywords: Malocclusion, Self esteem, Orthognathic quality of life, Dental Aesthetic Index, Rosenberg self esteem scale.

\section{Introduction}

With the increasing recognition of the effect of dentofacial problems, the social and psychosomatic consequences of malocclusion have been topics of research for a long time, but with conflicting results. ${ }^{1}$ The demand for orthodontic treatment in adults is rising with increase in the preventive outlook of the general dentistry nowadays, the esthetic demand of society, longevity of the population, access to information, technological advances in orthodontics and psycho-social variations. ${ }^{2-5}$

Studies show the malocclusion in adolescents has a potential negative impact on quality of life: higher dissatisfaction with appearance with increasing severity of malocclusion. ${ }^{1,6-8}$ Also, there is improvement of psychological profile with enhancement of aesthetics with orthodontic treatment. ${ }^{4,9,10}$ Thus, orthodontic treatment can improve not just an individual's appearance, oral health and function, but also psychosocial well-being, and the quality of life. ${ }^{11-13}$
Self-esteem is perception of one's own ability to effectively master or deal with the surrounding environment, and it is affected by the reactions of others towards an individual. ${ }^{14,15,16}$ Evidence has suggested that malocclusion can be associated with self-esteem and quality of life issues. ${ }^{7}$

Regarding dental appearance and the need for orthodontic intervention, there are considerable differences between the way a dental professional and a patient perceives. ${ }^{11}$ Likewise, the perception of esthetics and quality of life is different amongst patients, dentists and orthodontists. ${ }^{17}$ Dental students bridge between lay-persons and dentists. This study thus aims to determine the relationship between severity of malocclusion, self-esteem (SE) and orthognathic quality of life (OQOL) among female dental undergraduate students. The null hypothesis proposed was increasing grades of the course results in higher self-esteem and poorer quality of life amongst students pursuing on undergraduate course in dentistry. 


\section{Materials and Methods}

The study group was chosen amongst 121 female dental undergraduate students of the university screened on the basis of the following inclusion criteria: (1) age between 18 and 30 years (young adults); (2) no craniofacial anomalies, including cleft lip and/or palate; (3) no orthodontic treatment experience. All consecutive students that fulfill the selection criteria and signed the informed consent for participation were enrolled for the study.

The study sample consisting of 83 subjects was divided batchwise into four groups: 2nd year, 3rd year, 4 th year and Interns. To determine the severity of malocclusion, the subjects were examined by for Dental Aesthetic Index (DAI) score (Appendix 1). All subjects were then asked fill the questionnaires for self esteem (SE) and orthognathic quality of life (OQOL). (Appendix $2 \& 3$ ).

\section{Statistical analysis}

Descriptive statistics for DAI, SE and OQOL were performed and elements of each group were compared using ANOVA. Spearman Rank Correlation coefficient was done to measure the level of association between the variables.

\section{Results}

The mean age for the sample studied was $21.7 \pm 1.5$ years. 3rd year students presented with higher DAI and least OQOL score. Interns had higher SE and maximum OQOL.

ANOVA results showed only statistically significant difference between the groups for SE indicating more armour-propre with training and maturity. However, no significant correlation was noted between SE and OQOL. Results for Spearman rank correlation Batch, DAI, SE and OQOL indicated statistically significant negative correlation between DAI and OQOL, indicating more negative psychological impact of malocclusion with malocclusion.

Table 1: Batch wise descriptive statistics for DAI, SE, OQOL (Social Aspects, Esthetics, Function and Awareness Components of OQOL)

\begin{tabular}{|c|c|c|c|c|c|c|c|c|}
\hline BATCH & $\begin{array}{c}\text { Sample } \\
\text { Size (N) }\end{array}$ & DAI Score & SE & OQOL & $\begin{array}{c}\text { Social } \\
\text { Aspects } \\
\text { (OQOL) }\end{array}$ & $\begin{array}{c}\text { Esthetics } \\
\text { (OQOL) }\end{array}$ & $\begin{array}{c}\text { Function } \\
\text { (OQOL) }\end{array}$ & $\begin{array}{c}\text { Awareness } \\
\text { (OQOL) }\end{array}$ \\
\cline { 2 - 9 } & Mean \pm SD & Mean \pm SD & Mean \pm SD & Mean \pm SD & Mean \pm SD & Mean \pm SD & Mean \pm SD \\
\hline 2nd Year & 21 & $21.00 \pm 7.76$ & $25.90 \pm 3.55$ & $17.52 \pm 9.49$ & $6.05 \pm 4.32$ & $4.48 \pm 3.56$ & $1.86 \pm 2.07$ & $5.33 \pm 4.19$ \\
\hline 3rd Year & 22 & $22.01 \pm 5.36$ & $27.55 \pm 3.92$ & $13.50 \pm 10.30$ & $4.00 \pm 3.89$ & $3.05 \pm 2.11$ & $1.46 \pm 2.11$ & $5.28 \pm 4.48$ \\
\hline 4th Year & 19 & $22.74 \pm 5.89$ & $27.52 \pm 3.77$ & $17.26 \pm 14.05$ & $4.99 \pm 4.66$ & $5.57 \pm 4.96$ & $2.63 \pm 4.00$ & $4.26 \pm 2.54$ \\
\hline Intern & 21 & $20.15 \pm 6.53$ & $30.52 \pm 4.75$ & $18.90 \pm 18.10$ & $6.77 \pm 7.05$ & $5.10 \pm 5.35$ & $2.05 \pm 3.38$ & $5.29 \pm 4.52$ \\
\hline Total & 83 & $21.29 \pm 6.33$ & $27.96 \pm 4.36$ & $16.72 \pm 13.29$ & $5.40 \pm 5.17$ & $4.43 \pm 4.17$ & $1.90 \pm 2.90$ & $5.09 \pm 4.08$ \\
\hline
\end{tabular}

Table 2: Batch -wise comparison of Means using ANOVA for difference Between Groups

\begin{tabular}{|l|c|c|c|}
\hline \multicolumn{1}{|c|}{ Anova table } & DAI * batch & SE $*$ batch & OQOL * batch \\
\hline Sum of Squares & 54.56 & 1253.24 & 345.65 \\
\hline Df & 3 & 3 & 3 \\
\hline Mean Square & 18.25 & 15.95 & 115.28 \\
\hline F & 0.44 & 4.93 & 0.64 \\
\hline Sig. & 0.72 & $0.003 *$ & 0.589 \\
\hline
\end{tabular}

Table 3: Spearman's Rank Correlation b/t Batch, DAI, SE and OQOL for sample size N=83

\begin{tabular}{|c|l|c|c|c|c|}
\hline \multicolumn{5}{|c|}{ Correlations } \\
\hline \multirow{2}{*}{ DAI } & Spearman Correlation & Batch & DAI & SE & OQOI \\
\cline { 2 - 6 } & Sig. (2-tailed) & 0.19 & 1.000 & 0.16 & $-.25^{*}$ \\
\hline \multirow{2}{*}{ SE } & Spearman Correlation & 0.45 &. & 0.67 & 0.02 \\
\cline { 2 - 6 } & Sig. (2-tailed) & $.31^{* *}$ & 0.16 & 1.00 & -.39 \\
\hline \multirow{2}{*}{ OQOI } & Spearman Correlation & 0.00 & 0.69 &. & 0.18 \\
\cline { 2 - 6 } & Sig. (2-tailed) & -.04 & $-.25^{*}$ & -.29 & 1.00 \\
\hline \multirow{2}{*}{$\begin{array}{l}\text { *. Correlation } \\
\text { Correlation is significant at the 0.05 level; **. Correlation is significant at the 0.01 level; ***. }\end{array}$} \\
\hline
\end{tabular}




\section{Discussion}

In our study, self-esteem (SE) and orthognathic quality of life (OQOL) among female dental undergraduate students does relate to severity of malocclusion. The study was performed on young adults with the mean age for the sample $21.7 \pm 1.5$ years. ${ }^{12,13}$ To rule out the bias between the sexes, only female students were included in the study. Alsofemales are more concerned with beauty and have a better perception of treatment need as well as esthetic results. ${ }^{4,17,18}$

To measure the self-esteem (SE), Rosenberg self esteem scale (RSE) scoring was used. The RSE is a Likert scale in which a positive or a negative response is weighed with a four-point scale, ranging from "strongly agree" to "strongly disagree," and consists of 10 questions. The RSE was between 10 and 40, and a higher RSE score indicates greater SE. This scale has been used for both the general population and orthodontic patients. ${ }^{20,21}$

To measure the quality of life, orthognathic quality of life (OQOL) index was used, comprising of 22 questions that measure four principal components (social aspects, facial esthetics, function, and awareness of facial deformity) using a four-point scale. ${ }^{22}$ OQOL dimensions are scores range between 0 and 88 and the lower scores indicate better QOL. Although, originally designed to assess quality of life in dentofacial deformity patients, we used OQOL to cover all the issues that may bother a malocclusion patient especially when the subjects are dental students who are already aware and concerned for dental treatment.

Third year batch presented higher DAI score as well as least OQOL score indicating more malocclusion and lower quality of life. (Table 1). Spearman's Rank Correlation that also showed statistically significant negative correlation between DAI and OQoL score. (Table 3).

In concordance with earlier studies, that did reveal adolescents with higher DAI scores had greater esthetic impact scores, and adolescents with less attractive dentitions may be psychosocially disadvantaged and have esthetic concerns. ${ }^{23}$ Also, selfperceived impact of dental esthetics is influenced by severity of malocclusion, oral health-related quality of life, and body satisfaction. Malocclusion has been observed to have significant negative associations with QOL. ${ }^{6-11,24,25}$ However, weak correlations between the DAI and the oral health related quality of life, suggesting that the DAI grade cannot be considered strongly as predictor of the quality of life. ${ }^{26}$ Some also advocate with severe malocclusion do not report a negative impact, while others with mild irregularities cited major impacts on their QOL. ${ }^{12}$

Intern batch had higher SE score and maximum OQOL score. However no significant correlation was observed between SE and OQOL (Table 3). It has been reported that individuals with more self-esteem have poorer quality of life. ${ }^{27}$ Also, orthodontic treatment significantly improves SE as well as quality of life. ${ }^{5,28,29}$

Batch -wise comparison of means using ANOVA showed only statistically significant difference between the groups for self-esteem. This was also observed with Spearman's Rank Correlation that showed statistically significant positive correlation between the batch and Self-esteem. Increased SE with experience and age with increasing maturity and increasing consciuosness, more morale/ armour propre and hence more SE. ${ }^{30,31}$

Thus, the null hypothesis that increasing grades of the course results in higher self-esteem and poorer quality of life amongst students pursuing on undergraduate course in dentistry, holds accepted. However the limitations of this study must be taken into consideration. Perceptions of psychosocial impact related to dental esthetics are multi-factorial: specific socio-demographic characteristics such as type of education, demographic consideration, areas of residence, etc. may have resulted in potential bias for clinical and epidemiologic inferences. The subjects in this study were selected by convenience sampling: the sample amongst dental graduates is deficient in of individuals with severe malocclusion. Also a larger sample size would increase the sensitivity of the impact of malocclusion on SE and QOL.

\section{Conclusions}

Malocclusion does hamper the quality of life but increasing grades and cumulative understanding influence the self esteem amongst dental undergraduates.

\section{Source of funding}

None.

\section{Conflict of interest}

None.

\section{References}

1. Florián-Vargas K, Carruitero MJ, Bernabé E, Flores-Mir C. Self-esteem in adolescents with Angle Class I, II and III malocclusion in a Peruvian sample. Dent Press J Orthod 2016;21(2):59-64. DOI: http://dx.doi.org/10.1590/21776709.21.2.059-064. 
2. Capelozza Filho L, Braga AS, Cavassan AO, Ozawa TO . Orthodontic treatment in adults: an objective approach. Rev Dent Press Ortodon Ortop Facial 2001;6:63-80.

3. Alves e Silva AC, Carvalho RA, Santos Tde S, Rocha NS, Gomes AC, de Oliveira e Silva ED et al. Evaluation of life quality of patients submitted to orthognathic surgery. Dent Press J Orthod 2013;18:107-114.

4. Gazit-Rappaport T, Haisraeli-Shalish M, Gazit E . Psychosocial reward of orthodontic treatment in adult patients. Eur J Orthod 2010; 32:441-6.

5. Johal A, Alyaqoobi I, Patel R, Cox S. The impact of orthodontic treatment on quality of life and self-esteem in adult patients. Eur J Orthod 2015;37:233-7.

6. Marques LS, Ramos-Jorge ML, Paiva SM, Pordeus IA. Malocclusion: esthetic impact and quality of life among Brazilian schoolchildren. Am J Orthod Dentofacial Orthop 2006;129(3):424-7. doi: 10.1016/j. ajodo.2005.11.003 PMID: 16527640.

7. Feu D, de Oliveira BH, de Oliveira Almeida MA, Kiyak HA, Miguel JA. Oral health-related quality of life and orthodontic treatment seeking. Am J Orthod Dentofacial Orthop 2010;138:152-9. doi: 10.1016/j. ajodo.2008.09.033 PMID: 20691356

8. Scapini A, Feldens CA, Ardenghi TM, Kramer PF. Malocclusion impacts adolescents' oral health related quality of life. Angle Orthod 2013;83(3):5512-8. doi: 10.2319/062012-509.1 PMID: 23210545

9. Kolawole KA, Agbaje HO, Otuyemi OD. Impact of malocclusion on oral health related quality of life of final year dental students. Odontostomatol Trop 2014;37(145):64-74.

10. Clijmans M, Lemiere J, Fieuws S, Willems C. Impact of self esteem and personality traits on association between orthodontic treatment and oral health related quality of life in adults. Eur J of Orthod 2015;37(6):643-50.

11. Hunt O, Hepper P, Johnston C, Stevenson M, Burden D. Professional perceptions of the benefits of orthodontic treatment. Eur J Orthod 2001;23(3):315-23.

12. Palomares NB, Celeste RK, Oliveira BH, Miguel JA . How does orthodontic treatment affect young adults' oral healthrelated quality of life? Am J Orthod Dentofacial Orthop 2012;141:751-8.

13. Souza Ricardo Alves de, Oliveira André Frutuoso de, Pinheiro Suélem Maria Santana, Cardoso Jefferson Paixão, Magnani Maria Beatriz Borges de Araújo. Expectations of orthodontic treatment in adults: the conduct in orthodontist/patient relationship. Dent Press J Orthod [Internet]. 2013;18( ):88-94. [cited 2020 Feb 26]

14. Gecas V. The self-concept. Annu Rev Sociol 1982;8(1):133.

15. Rosenberg M, Schooler C, Schoenbach C, Rosenberg F. Global self-esteem and specific self-esteem: Different concepts, different outcomes. Am Soc Rev 1995;60(1):14156.

16. Haney P, Durlak JA. Changing self-esteem in children and adolescents: a metaanalytic review. J Clin Child Psychol 1998;27(4):423-33

17. McKeta N, Rinchuse DJ, Close JM. Practitioner and patient perceptions of orthodontic treatment: is the patient always right? J Esthet Restor Dent 2012;24(1):40-50.
18. Pabari S, Moles DR, Cunningham SJ. Assessment of motivation and psychological characteristics of adult orthodontic patients. Am J Orthod Dentofacial Orthop 2011;140:e263-e72.

19. Al-Omiri MK, Abu Alhaija ES . Factors affecting patient satisfaction after orthodontic treatment. Angle Orthod 2006;76:422-31.

20. Rosenberg, M. Society and the adolescent self-image. Princeton, NJ: Princeton University Press.1965.

21. Shaw WC, Richmond S, Kenealy PM, Kingdon A, Worthington H. A 20-year cohort study of health gain from orthodontic treatment: psychological outcome. Am J Orthod Dentofacial Orthop 2007;132:146-57.

22. Cunningham SJ, Garratt AM, Hunt NP. Development of a condition-specific quality of life measure for patients with dentofacial deformity: I. Reliability of the instrument. Comm Dent Oral Epidemiol 2000;28:195-201.

23. Delcides F. de Paula, Júniora; Nádia C. M. Santosa; Érica T. da Silvaa; Maria de Fa'tima Nunesa; Cla'udio R. Lelesb. Psychosocial Impact of Dental Esthetics on Quality of Life in Adolescents. Angle Orthod 2009;79:1188-93.

24. Masood Y, Masood M, Zainul NN, Araby NB, Hussain SF, Newton T. Impact of malocclusion on oral health related quality of life in young people. Health Qual Life Outcomes 2013;11:25. Published 2013 Feb 26. doi:10.1186/14777525-11-25.

25. Silva LFGe, Thomaz EBAF, Freitas HV, Pereira ALP, Ribeiro CCC, Alves CMC. Impact of Malocclusion on the Quality of Life of Brazilian Adolescents: A PopulationBased Study. PLoS ONE 2016;11(9):e0162715. https://doi.org/10.1371/journal.pone.0162715.

26. Ashari A, Mohamed AM. Relationship of the Dental Aesthetic Index to the oral health-related quality of life. Angle Orthod 2016;86:337-42. doi: 10.2319/121014-896.1.

27. Juth V, Smyth JM, Santuzzi AM. How do you feel? Selfesteem predicts affect, stress, social interaction, and symptom severity during daily life in patients with chronic illness. J Health Psychol 2008;13(7):884-94. doi:10.1177/1359105308095062

28. de Couto Nascimento V, de Castro Ferreira Conti AC, de Almeida Cardoso M, Valarelli DP, de Almeida-Pedrin RR. Impact of orthodontic treatment on self-esteem and quality of life of adult patients requiring oral rehabilitation. Angle Orthod 2016;88:1-7. doi: 10.2319/072215-496.1.

29. Olkun HK, Sayar G. Impact of Orthodontic Treatment Complexity on Oral Health-Related Quality of Life in Turkish Patients: A Prospective Clinical Study. Turk $J$ Orthod 2019;32(3):125-31. doi:10.5152/TurkJOrthod.2019.18042

30. Chung JM, Robins RW, Trzesniewski KH, Noftle EE, Roberts BW, Widaman KF. Continuity and change in selfesteem during emerging adulthood. J Pers Soc Psychol 2014;106(3):469-483. doi:10.1037/a0035135

31. Block J, Robins RW. A longitudinal study of consistency and change in self-esteem from early adolescence to early adulthood. Child Dev 1993;64:909-23.

How to cite: Nausheen $\mathrm{K}$, Madiha S, Kaur H. Impact of malocclusion on self-esteem (SE) and orthognathic quality of life (OQoL) amongst dental undergraduate students. Int Dent J Student Res 2020;8(1):14-7. 